\title{
DESFOLHAMENTO EM ESTÁDIOS DE DESENVOLVIMENTO DA SOJA, CULTIVAR BR 16, NO RENDIMENTO DE GRÃOS
}

\author{
DEFOLIATION AT DIFFERENT GROWTH STAGES OF SOYBEAN, \\ CULTIVAR BR 16, ON SEED YIELD
}

\author{
Ana Lúcia de Paula Ribeiro ${ }^{1}$ Ervandil Corrêa Costa $^{2}$
}

\section{RESUMO}

O estudo foi desenvolvido na Universidade Federal de Santa Maria, em Santa Maria, RS, no ano agrícola 1997/98, com a cultivar BR 16, sob o delineamento experimental blocos ao acaso com parcela subdividida e quatro repetições. $O$ objetivo deste trabalho foi avaliar a capacidade de produção da cultura da soja, submetida a desfolhamento em diferentes níveis $(0,17$ 33, 50, 67 e 100\%) e fases de seu desenvolvimento (V9, R3, R5 e R6) de acordo com a escala de FEHR \& CAVINESS (1977). Os níveis de 17, 33 e 50\% reduziram o rendimento final da soja em torno de 6\%, e os dois últimos 67 e 100\%, redução de 8 e $37 \%$ em relação a $0 \%$ de desfolhamento. Niveis de desfolhamento superiores a 50\% diminuem substancialmente o número de legumes e de grãos por planta de soja quando efetuados nos estádios de início de formação dos legumes (R3) e início do enchimento de grãos (R5). O peso de grão é reduzido mais drasticamente por desfolhas iguais ou superiores a $67 \%$ nos estádios R3 e R6.

Palavras-chave: desfolhamento artificial, soja.

\section{SUMMARY}

The work was carried out at the Federal University of Santa Maria, State of Rio Grande do Sul, in 1997/1998 using the cultivar BR 16. Statistical setup was a block design with subdivided plots, with 4 replications. The objective of this research was to evaluate the yield of the soybean variety BR16 when submitted to different defoliation levels $(0,17,33,50,67$ and $100 \%)$ and at different phases of development (V9, R3, R5 and R6) in agreement with the scale of FEHR \& CAVINESS (1977). The defoliation levels of 17, 33 and 50\% decreased seed yield by approximately 6\% and the last two levels 67 and 100\%, by about 8 and $37 \%$ in relation to $0 \%$ of defoliation. Levels of defoliation above $50 \%$ decrease the number of normal pods substantially and grains for plant when made at the beginning in the stadiums of formation of the pods (R3) and beginning of the formation of grains (R5). The reduction of grain yield was effected by the number of normal pods number of normal grains and weight of 100 seeds, which were the components most effected by the treatments.

Key words: artificial desfoliation; soybean.

\section{INTRODUÇÃO}

No Brasil, a produção de soja (Glycine max L.) concentra-se principalmente nas Regiões Sul e Centro Oeste. No Rio Grande do Sul, a área plantada em 1997 foi de 2.950 .930 ha, contribuindo com $20 \%$ da produção nacional, concentrando a produção nas microrregiões do Planalto Médio, Missões e Alto Uruguai (EMBRAPA, 1997).

Entre os fatores que podem interferir negativamente na produtividade da soja, destacam-se os insetos-praga, considerados os mais importantes. Estes causam prejuízos de forma direta, reduzindo a área fotossinteticamente ativa das plantas e indiretamente, como transmissores de doenças viróticas. O controle dos insetos-praga, na grande maioria dos casos, é realizado através de produtos químicos. $\mathrm{O}$ uso indiscriminado desses produtos pode causar problemas ecológicos e econômicos, sendo fundamental o conhecimento dos níveis de danos causados

\footnotetext{
${ }^{1}$ Engenheiro Agrônomo, MSc., Produção Vegetal, Departamento de Defesa Fitossanitária, Centro de Ciências Rurais (CCR), Universidade Federal de Santa Maria (UFSM), 97105-900, Santa Maria, RS. Autor para correspondência.

${ }^{2}$ Engenheiro Agrônomo, Doutor, Professor Titular, Departamento Defesa Fitossanitária, CCR/UFSM. Recebido para publicação em23.07.99. Aprovado em 19.01.00.
} 
pelos insetos, para serem utilizados como critério para racionalizar o uso de inseticidas químicos.

Trabalhos que simulem a ação desses insetos, especialmente no caso dos filófagos, visam a verificar os efeitos sobre o rendimento e ampliar os estudos que são ainda de número reduzido para as condições que ocorrem no Brasil. O estudo de níveis de danos de insetos pode ser realizado através da simulação, provocando-se o desfolhamento artificial nas plantas. A reação da planta de soja ao desfolhamento artificial é muito próxima da reação causada pelos insetos filófagos (GAZZONI, 1974).

A recomendação da pesquisa, baseada em trabalhos desenvolvidos na década de 70 a 80 , é controlar os insetos-praga quando os desfolhamentos forem superiores a $30 \%$ na fase vegetativa, ou $15 \%$ na fase reprodutiva. Os ensaios foram realizados com cultivares de pouca expressão para o Brasil, onde a maioria dos pesquisadores observaram que baixos níveis de desfolhamento não implicam reduções de produção (TURNIPSEED, 1972; GAZZONI \& MINOR, 1978; SALVADORI \& CORSEUIL, 1979) e desfolhamentos antes do florescimento, praticamente, não reduzem o rendimento de grãos, porém, acima desse nível, durante os estádios reprodutivos, causam maiores reduções na produção (RAMIRO \& OLIVEIRA, 1975; PISSAIA \& COSTA, 1982; DIOGO et al.,1997; GAZZONI \& MOSCARDI, 1998). Faz-se necessário considerar características como cultivares modernas, população de plantas e o sistema de cultivo, principalmente o plantio direto nas recomendações atuais para controle de insetos-praga.

Dessa forma, o objetivo deste trabalho foi avaliar a capacidade de produção de grãos da cultura da soja, cultivar BR 16, quando submetida a desfolhamentos em diferentes intensidades e fases de seu desenvolvimento.

\section{MATERIAL E MÉTODOS}

O estudo foi desenvolvido em Santa Maria RS, no ano agrícola 1997/98, em área experimental do Departamento de Defesa Fitossanitária na Universidade Federal de Santa Maria.

A semeadura foi realizada dia 25 de novembro de 1997, com auxílio de uma semeadora adubadora de cinco linhas para plantio direto e regulada para semear 20 sementes aptas por metro linear em solo classificado como Podzólico VermelhoAmarelo. A cultivar utilizada foi a BR 16.

O delineamento experimental foi de blocos ao acaso com parcela subdividida, com quatro repetições. O fator estádios de desenvolvimento foi casualizado nas parcelas principais, com área de $2,5 \mathrm{~m}$ x 15,0m. O fator níveis de desfolhamento artificial foi casualizado nas subparcelas, com área de $2,5 \mathrm{~m} \mathrm{x}$ $2,5 \mathrm{~m}$. Foi considerado como área útil, três linhas de 2,0m de comprimento, sendo que as duas linhas externas da cabeceira foram consideradas como bordaduras. $\mathrm{O}$ experimento foi composto de 24 tratamentos, resultante da combinação seis níveis de desfolhamento artificial (0, 17, 33, 50, 67 e 100\%) e quatro estádios de desenvolvimento da cultura (V9, R3, R5 e R6), segundo a escala FEHR \& CAVINESS (1977). Os níveis de desfolhamento foram aplicados em uma única oportunidade para cada estádio fenológico utilizando-se tesouras. Em cada trifólio retirou-se nenhum folíolo, meio folíolo, um folíolo, um folíolo e meio, dois folíolos e de todos os folíolos, correspondendo aos níveis de desfolha de $0,17,33,50,67$ e $100 \%$ respectivamente. Para obter dados referentes aos componentes do rendimento, foram utilizadas 20 plantas da linha central da parcela, as quais foram debulhadas manualmente. A partir dessas plantas, determinou-se valores médios para número de legumes normais, número de grãos normais e peso de 100 grãos (g). Conforme SALVADORI (1978), considerou-se como grão normal o grão de tamanho reduzido, mas que possuía forma esférica, e legume normal aquele que continha pelo menos um grão normal. $O$ peso do grão (100 grãos) foi obtido através da equação: peso dos grãos normais dividido pelo número de grãos normais multiplicado por 100 . As demais plantas foram trilhadas mecanicamente e determinou-se rendimento de grãos.

Efetuou-se análise de variância para verificar a significância da interação entre os níveis de desfolhamento e os estádios de desenvolvimento e dos efeitos individuais de cada fator. Realizou-se também a análise de regressão para os níveis de desfolhamento, que se constituíam no fator de maior relevância no estudo.

\section{RESULTADOS E DISCUSSÃO}

A análise da variância para rendimento de grãos não apresentou interação significativa entre estádios de desenvolvimento e níveis de desfolhamento. Efeitos significativos foram observados somente com relação ao nível de desfolhamento no rendimento de grãos. Foi realizada a análise de regressão entre rendimento de grãos e níveis de desfolhamento, evidenciando significativa relação entre essas variáveis (Figura 1). Os níveis de 17, 33, 50, 67 e $100 \%$ provocaram reduções no rendimento em torno de $6 \%$ para os três primeiros níveis, de 8 e de $37 \%$ para os demais em relação a $0 \%$ de desfolhamento, sendo esses percentuais obtidos através da 


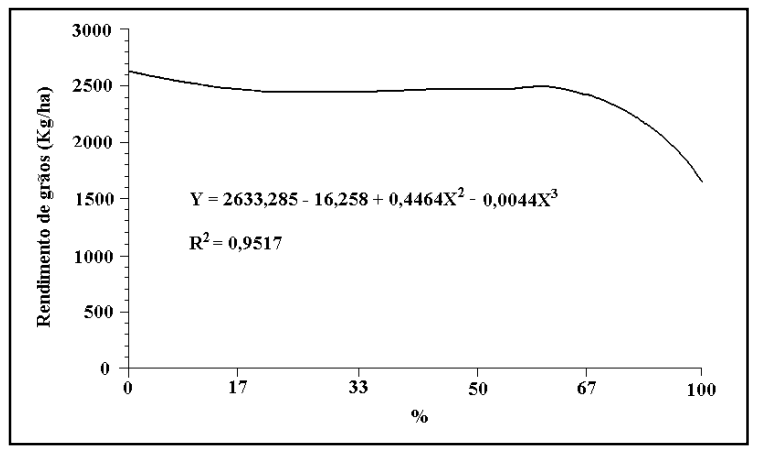

Figura 1 - Rendimento de grãos de soja (kg/ha), submetida a diferentes níveis de desfolhamento. Santa Maria - RS, 1999.

equação de regressão estimada. As diferentes respostas encontradas entre níveis de desfolhamento mostraram a capacidade das plantas em suportar uma determinada perda de área foliar, em todos os estádios fenológicos considerados. Com relação à perda de rendimento provocada pelo desfolhamento, HINSON et al. (1978) sugeriram que, além da redução de fotossíntese, há outros fatores envolvidos, como fixação de nitrogênio, principalmente nos níveis mais severos de desfolhamento.

Para o número de legumes normais por planta, a análise da variância mostrou que houve efeito significativo da interação entre níveis de desfolhamento e os diferentes estádios de desenvolvimento. A análise de regressão, que representa o comportamento dos níveis de desfolhamento dentro de cada estádio de desenvolvimento (Figura 2), evidenciou efeitos significativos com relação aos níveis de desfolhamento. As maiores reduções foram evidenciadas nos estádios R3 e R5. Para o estádio R3, desfolhamentos de 50, 67 e 100\% causaram reduções de 18,34 e $80 \%$, respectivamente, enquanto que no estádio R5 foram de 15, 25 e 48\%. O desfolhamento total nesses dois estádios foi mais prejudicial, porque as reservas das plantas são limitadas pela menor

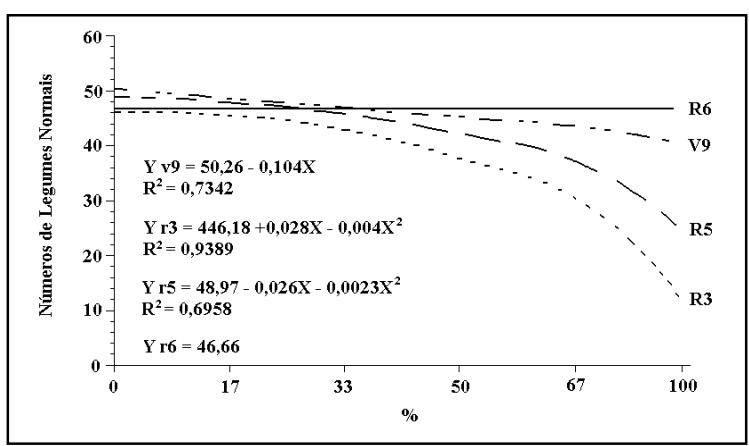

Figura 2 - Número de legumes normais, em soja submetida a reduções foliares, em diferentes estádios de desenvolvimento. Santa Maria - RS, 1999. capacidade da planta de regenerar o seu aparato fotossintético nessas etapas fenológicas

Observou-se, também, um comportamento linear decrescente do número de legumes normais com o aumento de desfolha em V9, contudo, esse efeito negativo pode ser compensado no restante do ciclo da cultura, fato este comprovado quando se comparam os resultados obtidos com $100 \%$ em V9, R3 e R5, que mostram que estes dois últimos apresentaram valores inferiores àquele, devido ao fato da planta ter condições de recuperação da sua área foliar, quando desfolhada em V9, recuperando assim sua capacidade fotossintética.

Com relação à variável número de grãos normais por planta, a análise da variância apresentou interação significativa entre os níveis de desfolhamento e diferentes estádios de desenvolvimento. Com o aumento da intensidade de remoção das folhas, observaram-se reduções significativas em todos os níveis de desfolhamento para os estádios V9 e R3 (Figura 3). No estádio V9, houve respectivamente $4,7,10,13$ e $19 \%$ de redução, sendo esta de comportamento linear. Durante o período reprodutivo R3, os resultados indicam uma redução de 4, 11, 23, 38 e $80 \%$ para os níveis de desfolhamento, observando-se que esse estádio apresenta o menor número de grãos normais, comprovando que o decréscimo na atividade fotossintética e, por conseguinte, redução na quantidade de fotoassimilados produzidos pela planta, afeta a produção de grãos normais. Desfolhamentos de 50, 67 e 100\% mostram a interferência negativa desses níveis na fase de formação de legume. A alteração da fotossíntese em qualquer período durante o florescimento e a formação de legumes afetará o número de grãos, segundo HARDMAN \& BRUN (1971), embora não esteja claro se alguns períodos são mais críticos que outros (SCHOU et al. 1978).

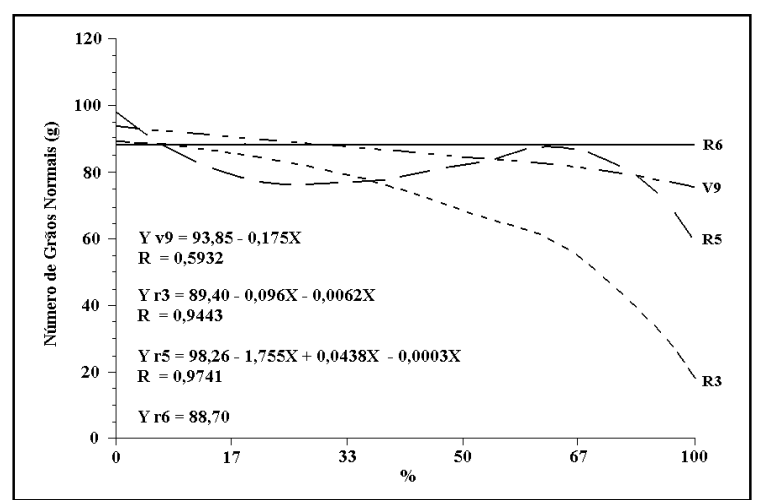

Figura 3 - Número de grãos normais, em soja submetida a reduções foliares, em diferentes estádios de desenvolvimento. Santa Maria - RS, 1999. 
Para o estádio R6, o número de grãos normais manteve-se constante, pois as plantas acumularam reservas durante o desenvolvimento vegetativo para translocar aos grãos durante o período reprodutivo. No estádio R5, a redução ocorreu nos níveis de desfolhamento 17, 33 e $100 \%$ com 19, 21 e 38\%. Observando-se, no entanto, um acréscimo no número de grãos com os níveis de desfolhamento 50 e $67 \%$, quando comparados aos demais tratamentos, de aproximadamente 16 e $11 \%$ em relação ao nível de $0 \%$. Esses resultados concordam em parte com PISSAIA \& COSTA (1982) que encontraram acréscimos com desfolhamento de $67 \%$.

Segundo HANWAY (1976), a maior exigência de produtos da fotossíntese e de nutrientes é entre os estádios R4 e R5, período em que está se processando o acúmulo de matéria seca nos grãos, sendo que HANWAY \& THOMPSON (1971) citam que as reservas acumuladas durante o desenvolvimento vegetativo das plantas são translocadas aos grãos durante esse período.

No peso de cem grãos, verificou-se que a interação entre os níveis de desfolhamento e estádios de desenvolvimento foi significativa. A análise de regressão (Figura 4) apresenta os resultados nos quais os desfolhamentos de 17, 33 e 50\%, no estádio $\mathrm{R} 3$, provocaram um acréscimo no peso de cem sementes de respectivamente 4, 5 e $3 \%$. Estes acréscimos no peso dos grãos durante o estádio R3 podem ter ocorrido porque as plantas já se encontravam em pleno desenvolvimento vegetativo, e com reservas de carboidratos armazenadas suficientemente para o desenvolvimento inicial das estruturas reprodutivas.

No estádio R6, desfolhamentos de 50, 67 e $100 \%$ provocaram reduções de 5,7 e $14 \%$, respectivamente. No caso do peso do grão, os resultados confirmam, em parte, com SALVADORI \& CORSEUIL (1979) que relatam não haver reduções devido ao desfolhamento, pois verificaram este comportamento nos estádios V9 e R5.

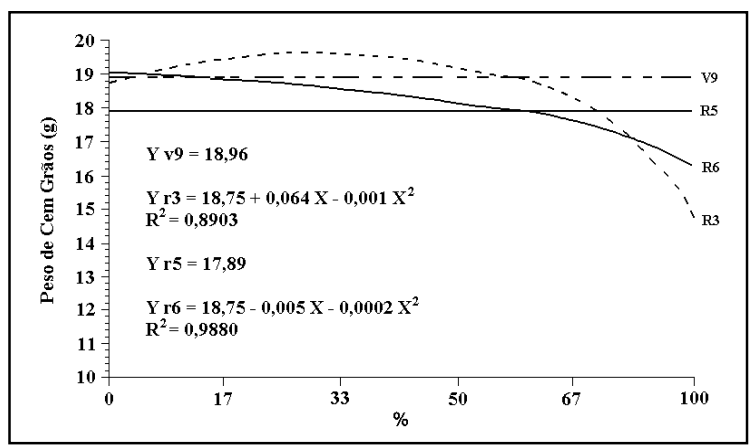

Figura 4 - Peso de cem grãos (g), em soja submetida a reduções foliares, em diferentes estádios de desenvolvimento. Santa Maria - RS, 1999.

\section{CONCLUSÕES}

Para a cultivar de soja BR 16, nas condições do presente estudo, pode-se concluir que:

o rendimento diminui com desfolhamentos acima de $67 \%$, desconsiderando os estádios de desenvolvimento;

níveis de desfolhamento superiores a $50 \%$ diminuem substancialmente o número de legumes e de grãos por planta de soja quando efetuados nos estádios de início de formação dos legumes (R3) e início do enchimento de grãos (R5);

o peso de grão é reduzido mais drasticamente por desfolhas iguais ou superiores a $67 \%$ nos estádios R3 e R6.

\section{REFERÊNCIAS BIBLIOGRÁFICAS}

DIOGO, A.M., SEDIYAMA, T., ROCHA, V.S., et al. Influência da remoção de folhas, em vários estádios de desenvolvimento, na produção de grãos e em outras características agronômicas da soja (Glycine max (L.) Merrill). Revista Ceres, Viçosa, v.44, n.253, p.272-285, 1997.

EMBRAPA. Centro Nacional de Pesquisa de Trigo (Passo Fundo, RS). Soja: resultados de pesquisa do Centro Nacional de Pesquisa de Trigo, 1996/97. 172p. (Embrapa-CNPT. Documentos, 35). Trabalhos apresentados na XXV Reunião de Pesquisa de Soja da Região Sul, Passo Fundo, RS, 1997.

FEHR, W.R., CAVINESS, C.E. Stages of soybean development. Ames: Iowa State University, 1977. 12p. (Special Report, 80).

GAZZONI, D.L. Avaliação de efeito de três níveis de desfolhamento aplicados em quatro estádios de crescimento de dois cultivares de soja (Glycine $\max$ (L.) MERRILL), sobre a produção e a qualidade do grão. Porto Alegre, RS 70p. Dissertação (Mestrado em Fitotecnia) - Curso de Pósgraduação em Agronomia, Universidade Federal do Rio Grande do Sul, 1974.

GAZZONI, D.L., MINOR, H.C. Efeito do desfolhamento artificial sobre o rendimento e os seus componentes. In: I SEMINÁRIO NACIONAL DE PESQUISA DE SOJA, 1978, Londrina, PR. Anais... Londrina : EMBRAPA/CNPS, 1978. 381p. p.47-57.

GAZZONI, D.L, MOSCARDI, F. Effect of defoliation levels on recovery of leaf area, on yield and agronomic traits of soybeans. Pesquisa Agropecuária Brasileira, Brasília, v.33, n.4, p.411-424, 1998 .

HANWAY, J.J. Interrelated developmental and biochemical, process in the growth of soybean plants. In: HILL, L.D., (ed). World Soybean Research. Danville : Interstate, 1976. p.515 .

HANWAY, J.J.; THOMPSON, H. How a soybean plant develops. Ames: Iowa State University Cooperative Extention Service, 1971. 17p. (Special Report, 53).

HARDMAN, L.L., BRUN, W.A. Effect of atmospheric carbon dioxide enrichment at different development stages on grow and yield components of soybean. Crop Science, Madison, v.11, p.886-888, 1971. 
HINSON, K., NINO, R.H., BOOTE, K.J. Characteristics of removed leaflets and yield response of artificially defoliated soybeans. Soil and Crop Sciense Society of Florida Proceedings, Walton Beach, v.37, p.104-109,1978.

PISSAIA, A.; COSTA, J.A. Influência de desfolhamentos artificiais sobre o rendimento de grãos e seus componentes, em duas cultivares de soja. Pesquisa Agropecuária Brasileira, Brasília, v.17, n.6, p.873-881, 1982.

RAMIRO, Z.A., OLIVEIRA, S.A. Influência da desfolhação artificial na produtividade da cultura da soja. O Biológico, São Paulo, v.41, n.4, p.97-104, 1975.

SALVADORI, J.R. Efeito de quatro níveis de desfolhamento aplicados em quatro estádios de desenvolvimento da soja (Glycine $\max ($ L.) MERRILL), na produção de grãos. Porto Alegre-RS, 1978. 88p. (Mestrado em Fitotecnia)-
Curso de Pós-graduação em Agronomia, Universidade Federal do Rio Grande do Sul, 1978.

SALVADORI, J.R., CORSEUIL, E. Efeito de quatro níveis de desfolha aplicados em quatro estádios de desenvolvimento da soja (Glycine $\max$ (L.) MERRILL), na produção de grãos. Agronomia Sulriograndense, Porto Alegre, v.15, n.1, p.91101,1979 .

SCHOU, J.B., JEFFERS, D.L., STREETER, J.G. Effects of reflectors, black boards, or shades applied at different developmental stages on growth and yield components of soybeans. Crop Science, Madison, v. 18, p.22-34, 1978.

TURNIPSEED, S.G. Response of soybeans to foliage losses in South Carolina. Journal of Economic Entomology, Maryland, v.65, n.1, p.224-229, 1972.

Ciência Rural, v. 30, n. 5, 2000. 